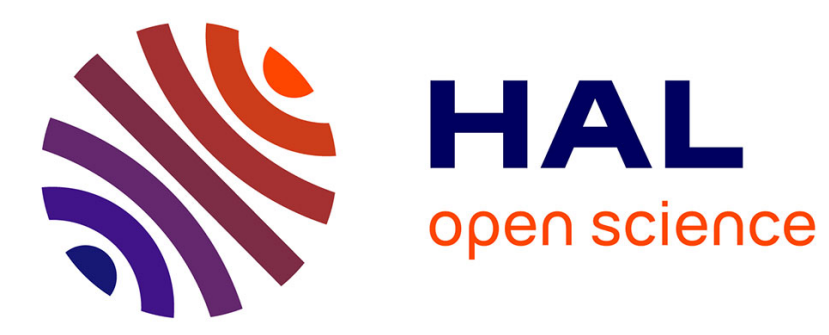

\title{
Seeing What We Build Together: Distributed Multimedia Learning Environments for Transformative Communications
}

Roy D. Pea

\section{> To cite this version:}

Roy D. Pea. Seeing What We Build Together: Distributed Multimedia Learning Environments for Transformative Communications. The Journal of the Learning Sciences, 1994, 3(3), pp.285-299. hal00190574

\section{HAL Id: hal-00190574 \\ https://telearn.archives-ouvertes.fr/hal-00190574}

Submitted on 23 Nov 2007

HAL is a multi-disciplinary open access archive for the deposit and dissemination of scientific research documents, whether they are published or not. The documents may come from teaching and research institutions in France or abroad, or from public or private research centers.
L'archive ouverte pluridisciplinaire HAL, est destinée au dépôt et à la diffusion de documents scientifiques de niveau recherche, publiés ou non, émanant des établissements d'enseignement et de recherche français ou étrangers, des laboratoires publics ou privés. 


\title{
Seeing What We Build Together: Distributed Multimedia Learning Environments for Transformative Communications
}

\author{
Roy D. Pea \\ Northwestern University
}

\begin{abstract}
We cannot really understand how to create computer support for collaborative learning without first becoming clearer about what we mean by communication, collaboration, and learning. After distinguishing several conceptions of communication, and highlighting transformative communications for learning, I consider how, via broadband telepresence, distributed multimedia learning environments may establish such communications by adequately acknowledging the social and material embeddedness of everyday communication. I then describe high-priority areas for advancing this agenda: in sociocultural theory, in examining conceptual change by means of conversational analysis, and in technically establishing affordances of tools to sustain and potentially enhance joint activity beyond the here-and-now and the face-to-face.
\end{abstract}

Although anticipated in Doug Engelbart's prescient work in the late 1960s, during the past 5 years a new development has emerged in computer technologies that has been characterized as computer-supported collaborative work (CSCW). Concerned with identifying, exemplifying, and empirically examining the designs of tools that may contribute to the achievement of collective activity, this subfield of research on human-computer interaction has spawned (or perhaps begun to merge with) new studies of what some have called computer-supported collaborative learning (CSCL). In a field beset with acronyms, it seems important to get the concepts right before we abbreviate their terms. In this spirit, I believe that computer support for collective learning is truer to experience, because not all learning together

Requests for reprints should be sent to Roy D. Pea, Northwestern University, School of Education and Social Policy, 2115 North Campus Drive, Evanston, IL 60201. 
feels or probably is collaborative; it is sometimes competitive or coercive in nature. I also believe that "collective" is more minimally descriptive.

In this article, I highlight a constructive orientation on the processes and products affiliated with collective learning--emphasizing that a central activity of learning is the construction and refinement by learners of documents, problem interpretations, models, analyses, and so on, in the context of their goal-related activities. I also emphasize the need for seeing what we build as a crucial goal for CSCL design. Collective learning will grow from designs for mutual reference in which texts, data, graphic displays, models, and the like that we are working on as joint objects are also held in common view. Then we can elaborate and refine those objects as we would in face-toface interaction, and perhaps even in superior ways. I stress the together, the collective, which is evident in the focus on joint activity. After these preliminaries, I turn to issues of communication, and then to their implications for the design of distributed multimedia learning environments.

\section{SOCIAL AND MATERIAL EMBEDDEDNESS OF EVERYDAY COMMUNICATION}

Conversations and interactions in everyday life take place in a rich referential field. The dense texture of human bodily orientation, gesture, and facial expression are known to communicate and continually transform on a moment-to-moment basis affective, cognitive, and social dimensions of relationships. Just as profoundly, there is a material environment to which attention can be directed, by gaze, pointing, and other means, in this conversational space. It, too, is transformed on a moment-to-moment basis. This material environment certainly includes physical objects, but it is also likely to include external representations, or inscriptions, such as writing and sketches, and in more formal settings, whether in school or work, such symbolic artifacts as equations, diagrams, maps, and designs. Both the literal physical shape and the interpretation of this material world tend toward change over the course of human conversational interactions. What am I referring to, and what should you take me to mean by what I do with and say about it? The achievement of human communicative activity is, in an important sense, coextensive with these transformations of beliefs and environments. If no change took place, one would be hard pressed to say that communication had occurred.

The consequences of the social and material embeddedness of meaningmaking in human interaction are deep ones for conceptualizing CSCL and have not been sufficiently attended to, either in theory or in design of systems for supporting such activities. Most important, they imply the need for highly interactive, multimedia conversational learning environments (Cruz, Gomez, \& Wilner, 1991; Pea \& Gomez, 1992). But before examining these implications, we must examine two concepts of communication. 


\section{TWO CONCEPTS OF COMMUNICATION}

I have alluded to a neglect of the social and material embeddedness of everyday communication in studies of educational computing generally. A fundamental reason for this neglect lies in the root metaphor of communication as transmission of information. James Carey (1989) described two contrasting definitions of communication in the history of Western thought: a transmission view and a ritual view. He claimed Dewey (1916) exploited such a contrast in such enigmatic comments as "Society exists not only by transmission, by communication, but it may be fairly said to exist in transmission, in communication" (p. 5). Carey argues that both definitions surfaced in common discourse as recently as the 19th century and that the transmission view had primarily political and mercantilistic origins and the ritual view, religious origins. The more common, dominant, and dictionaryprimary view of communication as transmission centers on the ancient practice of transmitting messages over distance in order to exert control, first through oral messengers, later through written languages, later yet by telegraph, and now by telecommunications. Its religious root is the worship service. The minority, even archaic, view of communication as ritual is associated with terms such as participation, sharing, taking part, fellowship, and association. As Carey (1989) claims: "a ritual view of communication is directed not toward the extension of messages in space but toward the maintenance of society in time; not the act of imparting information, but the representation of shared belief" (p. 18). The contrast, as Carey aptly frames it, is one in which society creates symbolic forms - writings, dance, theater, architecture, science-that operate to provide confirmation not information and thus the "construction and maintenance of an ordered, meaningful cultural world" (pp. 18-19).

These two definitions of communication lead to different questions and concerns in examinations of communicative action for learning. If we take reading as an example, the view of communication-as-transmission asks about the learner's acquisition of information conveyed by the text, the effects received by the learner from messages transmitted by the writer. The view of communication-as-ritual focuses instead on the dramatic participation of the learner in the views and social roles of the world portrayed. The reader is more like a member of the audience at a Balinese cockfight described by Clifford Geertz (1973) than the recipient of information from the author of the text.

This ritualistic view appears to take on a more obvious illuminating role in examinations of real time, face-to-face interaction. In the past several decades, the insights of Berger, Garfinkel, and other theorists such as Bateson, Burke, Geertz, and Goffman have led to an increasingly rich tradition of conversational and interactional analysis research (Goodwin \& Heritage, 1990). These social scientists have theorized about and documented the construction and continual interactional maintenance of social order by means of seemingly ordinary conversations in everyday life. 


\section{TRANSCENDING THE TRANSMISSION VIEW IN EDUCATION: FROM THE RITUALISTIC TO THE TRANSFORMATIVE}

These contrasting views of communication provide a powerful dialectical opposition for conceiving of communicative action. Although neither alone captures the whole truth about communication, it is evident that the transmission view has largely reigned in educational practice. This one-way view of information conveyed by authorities to knowledge produced in (not by) the learner must be enriched for a vital education to occur.

It is difficult to appropriately understand even the transmission aspects of communication in absence of the ritualistic. In a famous passage, Dewey framed the reason we must not limit our attention to the transmission view of communication:

There is more than a verbal tie between the words common, community, and communication. Men live in a community in virtue of the things which they have in common; and communication is the way in which they come to possess things in common. What they must have in common ... are aims, beliefs, aspiration, knowledge - a common understanding-likemindedness as sociologists say. Such things cannot be passed physically from one to another like bricks; they cannot be shared as persons would share a pie by dividing it into physical pieces. ... Consensus demands communication. (Dewey, 1916, pp. 5-6)

But although it is two-way in its emphases, the foregrounding of a ritual view of communication is in itself not sufficient. Ritual is certainly important in the significance it attaches to participation and belonging and its highlighting of social roles, but it does not establish generativity of the kind required for education. Because learning is not only a conserving enterprise, which seeks ritual belonging in order to perpetuate sameness and tradition, it is also a quest to expand the ways of knowing. It seeks to expand the problem niches to which past concepts and strategies and beliefs are applied. It must establish in its communicative activities the grounds for its own evolution.

I therefore propose describing this third view of communication as transformative. The initiate in new ways of thinking and knowing in education and learning practices is transformed by the process of communication with the cultural messages of others, but so, too, is the other (whether teacher or peer) in what is learned about the unique voice and understanding of the initiate. Each participant potentially provides creative resources for transforming existing practice, in going beyond the common body of knowledge of the field in their inquiries and the conceptual tools developed to sustain these practices.

\section{VIEWS OF COMMUNICATION IN EDUCATIONAL COMPUTING}

Let us return to the educational computing community, in which the intellec- 
tual tradition of the transmission view of communication has been inherited, most commonly without acknowledgment of either its commitments or its limitations. This neglect is particularly evident in the field of intelligent tutoring systems. These programs presuppose the task of education to be one of diagnosing the faulty misconceptions and information of the learner and replacing them with the veridical information that can be delivered by the tutoring component of the system. Instructional design methods for curriculum also speak of the delivery of courseware, whether in stand-alone computers, in networked integrated learning systems, or in other media. Research on the effects of media on learning - whether computing, television, or writing systems - by their very framing of the question in terms of effects also inherit the transmission orientation. This underlying communication perspective is no less apparent in various multimedia electronic books and CD-I paradigms now emerging, which profess that learning occurs by browsing, guided exploring, and other forms of exposure to information resources.

More recent views of educational communication in terms of conceptual learning conversations (Pea, 1992, 1993), cooperative learning, cognitive apprenticeship (Collins, Brown, \& Newman, 1989), communities of learning (Brown \& Campione, in press), knowledge-building communities (Scardamalia \& Bereiter, in press), and learning as legitimate peripheral participation (Lave \& Wenger, 1991) implicitly recognize the need for foregrounding a ritualistic view of communication. When they invoke the notion of learners participating in inquiries at the frontiers of knowledge in a field and with mature communities of practitioners in a discipline, they endorse a view of communication for learning that I describe as transformative. Yet interpretations of apprenticeships and collaborative learning may vary because they can be characterized by either a transformative point of view on communication or an implicit transmission view. In those interpretations characterized by an implicit transmission perspective, the goal is viewed as one of creating good strategies in pedagogic practice to make sure the right information is transmitted or in neo-Piagetian terms, constructed by the learner. Even among constructivists, there is often lack of recognition that such communicative interchanges transform not only the child but also the expert in the communicative system-the teacher.

When communication is viewed from this transformative perspective, not only students but also teachers are transformed as learners by means of their communicative activities. It is a two-way dynamic system, with important implications for what we consider changing to support transformative communications in the learning environment. ${ }^{1}$ Students are not blank slates written on with curricular lessons. They are active learners who have, by participating in various cultural practices, developed substantial beliefs and ways of thinking before ever coming to school. These existing conceptions and strategies are often best met and negotiated by the teacher in a conversation. They are poorly dealt with by seeking to overwrite them with lectures 
and demonstrations. Nor are teachers simply broadcasters of the information available in a curriculum. It takes significant effort for a teacher to understand what students are thinking about new learning topics. They may well develop new understandings of the subject domain by seeing how students have spontaneously come to think about it and what surprising inferences they may draw. It is hard for students to determine what teachers are attempting to communicate through their activities. For the social construction of understanding to take place, these interpretive activities are of necessity highly interactive conversational exchanges requiring conjectures, responses, and repairs for all participants to determine what is meant from what is said and done (Pea, 1992, 1993). This style of discourse is too rare in educational practice, but it certainly exists and can be sustained, as evidenced in Lampert and Ball's teaching of mathematical argumentation in elementary school and Minstrell's physics instructional conversations.

\section{SYMBOL SYSTEMS FOR MULTIMEDIA LEARNING ENVIRONMENTS}

A rich variety of media are needed for learning conversations, embodying symbol systems as diverse as photographs, animated scientific diagrams, maps, mathematical notations, graphs, texts, and films (Pea, 1991b). The symbol systems used for communication, as Geertz, Goodman, and others have observed, have the crucial properties of simultaneously providing representations of and for reality. As symbols-of, they synoptically represent reality. As symbols-for, they create the reality they present-either as prescriptions to change the world (blueprints) or as environments to work within (as in maps, graphs, or models). From either perspective, communications using these symbol systems are open to multiple interpretations in how they express representations of or for reality. Thus it often takes substantial interactional work, turn taking, and repair among conversational participants to establish a common ground of understanding.

\section{TOWARD DISTRIBUTED MULTIMEDIA LEARNING ENVIRONMENTS FOR TRANSFORMATIVE COMMUNICATIONS}

Changes in communication technologies thus influence what messages can

\footnotetext{
'John Bransford (personal communication, January 18, 1993) suggests that "in research, for example, an implication of the transformation view is that we should not simply measure texts and teaching techniques in terms of how well they lead students to 'correct answers.' Instead, we would also measure them in terms of how well they help students explicate their thinking, and hence, give teachers insights into the thinking of their students."
} 
be produced (e.g., text, audio, multimedia, in-context annotations). They also shape how interactively their meanings can be established and transformed (e.g., synchronously or not). In designing and utilizing computer supports for collective learning, there is thus a great responsibility involved. We are essentially creating the infrastructure for these assertions and negotiations of meaning. For learning and education, such an infrastructure must sustain (and perhaps even augment) transformative and not only transmissional communications.

For example, it is only in a limited sense of broadcast transmission that filmstrips or television broadcasts are communicative. Uses of these media for learning can benefit greatly from human interactional exchanges that use them as topic. In earlier eras of enthusiasm over the potentials of using media to deliver content for instructional purposes, learning participants were left out or given a diminished communicative role in the learning equation. The discourse of learning in formal education even developed exotic conversational forms-question, answer, evaluation-and limited views on the development of knowledge and understanding (multiple choice testing) to canonize these restrictions.

So when we see distance-learning projects using satellites or fiber optics cable for reproducing the lecture through remote audiovisual telephones, we are worried (Pea \& Gomez, 1992). We are as concerned about students' prospects for learning with minimal participant interactivity as many critics rightfully were when educational television emerged. These distance-learning projects primarily allow the remote chaining of classrooms to accomplish distributed traditional lectures. The teacher is physically separate from some or all students. The lecture is broadcast to one or more remote classrooms. In most situations video communication is one-way from the teacher. Students ask questions and otherwise interact with instructors via audio callback channels. In rare cases, teachers have two-way audio and video, but even then, it is the teacher with control over which remote class is seen and heard. Current distance-learning systems and prototypes do not have facilities for small-group interaction. Teachers cannot interact with a small group of students to the exclusion of others. Similarly, students who use these systems cannot establish small remote in-class collaborative teams to work on some aspect of problems at hand. For the most part, data are not integrated into the distance-learning experience. Remote students may see examples projected on monitors, but they cannot interact with these examples at the board. The teacher can ask multiple choice questions and students can respond yes/no with a remote control. Only crude approximations of learners' understandings can be attained in this manner. The bandwidth for transformative communications is considerably reduced from the possibilities in proximal physical learning environments.

Even the most modern desktop audiovisual communications systems, such as Bellcore's Cruiser (Fish, Kraut, Root, \& Rice, 1993), Xerox PARC's VideoWhiteBoard (Tang \& Minneman, 1991), and Xerox EuroPARC's Poly- 
scope/Vrooms (Borning \& Travers, 1991), have not accomplished the sort of full integration of media needed by distributed multimedia learning environments. These systems provide very flexible personal two-way video communication, but they too have not solved the problem of integrating data communications with audiovideo telephony.

In short, today's distance-learning technology and even modern desktop teleconferencing fail to create with telepresence a great many of the important aspects of transformative communication for learning. The telecommunications and multimedia technologies per se are not the central issue for learning. It is specific kinds of activities taking advantage of the offerings of the technology that will be likely to pay off. Any cognitive effects the computer interventions may have are mediated in significant ways by the communicative activities in the social environment, and they center on transformative communication. Our media technologies need to be vivified to match highly interactive conversational needs. They should allow for the expansion of these transformative capacities of human communication for learning within and across schools. They should utilize resources for learning latent within activities of communities outside of school, and whenever possible, they should seek to identify opportunities in which systems could more powerfully support transformative communications than do face-toface interactions, as in the cumulative knowledge building and reflection that can take place in a networked community of learners such as Scardamalia and Bereiter's computer-supported learning environments (CSILE) program (1991).

\section{NECESSARY ADVANCES}

It is one issue to recognize the need to place in the foreground transformative communication for learning and quite another to cope with its vast implications. We must begin to define a science of interactive learning environments that seriously embraces conversational and interactional analysis as a means of understanding the transformations of learner and teacher meanings that take place in and around computer-based technologies. Three developments are required to provide this shift with substantial foundations. One concerns the concepts of communities and cultures for learning. The second concerns integrating research on conceptual change and conversational analysis. The third involves addressing the design and technical issues necessary to advance testbeds for creating and studying highly interactive, distributed multimedia environments.

The first development needed will be a greater elucidation of the concepts of communities and cultures. Social science has struggled with definitional issues for these constructs for at least a century, particularly in critical sociology in recent times, so the clarification will not come easily. Yet activities such as collaborative networks for project-enhanced science learn- 
ing call for cognitive apprenticeships using authentic tasks from communities of practice, and teleapprenticeships call for some clarity on these issues (Hawkins, 1991; Lave \& Wenger, 1991; Levin, Riel, Miyake, \& Cohen, 1987; Newman, Griffin, \& Cole, 1989; Riel \& Levin, 1990; Rubin, 1992; Ruopp et al., 1993; Tinker, 1992; Waugh \& Levin, 1989). Who shall be connected to whom, from what communities, for what purposes? What shall be the participation protocols for new networked learning environments?

A second development requires the meeting of two currently distinct bodies of research - on conceptual change and on conversational analysis (Pea, 1993; Roschelle, 1993). This development is required to firmly ground the notion I have been promoting of conceptual learning conversations, in which students use symbols and terms in authentic activities (e.g., predictions, explanations for scientific inquiry) in small groups, during which meaning alignments and conceptual change are made possible through conversational repair and appropriation of learner activities (Pea, 1992). Technologies can play special roles in representing dynamic concepts for establishing co-reference among participants in these conversations (Pea, Sipusic, \& Allen, in press). We have developed this perspective, which includes cognitive, interactional, and (science) community levels of analysis, in a National Science Foundation classroom-based research and development effort we call the Dynagrams Project. This enterprise first documented existing teaching-learning practices and learning outcomes in introductory geometrical optics and then designed diagram-based computer microworldenhanced learning activities (i.e., dynagrams or dynamic diagrams), and studied the cognitive, interactional, and social outcomes of this redesigned learning environment (for details, see Pea, 1991a, 1992; Pea et al., in press). We investigated the use of diagrams in science learning and how computer technologies might enhance the roles of diagrammatic representations in science learning. Our curriculum topic was introductory geometrical optics - in particular, image formation with mirrors and lenses.

The project was organized in three phases. In the first, we studied how diagrams were used and understood for geometrical optics in two exemplary high school classrooms in New York and in California. This research included videotaping expert teachers' use of diagrams for science education and individual students' use of diagram problem representation and topic understanding as they thought aloud and solved optics problems with diagrams at a chalkboard. Our initial expectation was that by documenting the practice of expert teachers in helping students come to reason diagrammatically, we could then seek to replicate and even improve learning-teaching processes for other teachers by creating dynamic diagramming tools to make this teaching process simpler. Instead, we found teaching and learning for the test, memorization of diagram cases rather than learning mental models for diagrammatic reasoning, and minimal uses by learners of diagrams and affiliated concepts and strategies in optics in appropriate contexts of application for problem solving and prediction. In addition, we documented 
serious naive misconceptions concerning light and vision. Learners' notions did not sufficiently recognize the nature of ray sprays for reasoning about image formation or the role of the eye as detector of ray sprays in image formation. These models appeared minimally influenced by instruction. We also conducted detailed analyses of the physics as taught - teachers used diagrams in lectures, demonstrations, and labs mainly to exemplify concepts, rather than as reasoning tools for predicting and understanding the behavior of light, reflectors, absorbers, and the like. Essentially, students were faced with an impoverished discourse environment for ever coming to use diagrams as conceptual reasoning tools-they did not see the teachers using them this way, and they had little or no opportunity to use them this way themselves.

In the second phase, we took these results to influence the design and implementation of optics dynagrams-technology-enhanced teaching and learning activities. Central to these was a set of challenge activities and inquiry projects integrating learning with an optics simulator we created, which included a dynamic diagram (dynagram) construction kit, hands-on optical tools, and videotape with optical situations and related explanatory animations for scientific visualization. These activities involved continual mapping between real-world experience of optical situations and formal representations of optics concepts and relations (ray diagrams). The physics educators, learning experts, and software designers on our team worked closely together to ground minute details of design decisions for the software on the basis of what we had learned were specific difficulties for students. For example, we created a ray spray tool to emphasize thinking of ray sprays from an object point, which we predicted would contribute to reducing misconceptions of image formation in terms of light conceived as parallel beams.

The 2-D optics dynagrams simulator we developed allowed students to create and manipulate easily one or more scenes made up of optical entities such as spherical, triangular, and rectangular objects (that have assignable properties: materials; reflecting, absorbing, refracting). One could also emit single light rays or ray sprays over an angle range from one or more point light sources. Students could create geometrical entities, such as tangent lines, grids, and angles, and measure distances and angles. We largely focused on promoting qualitative understanding of relations in geometrical optics (e.g., to define shadows, find image location, find lines-of-sight for mirrors), rather than formal quantitative principles and formulas.

We then used the dynagrams simulator to create a set of challenge activity structures of increasing complexity (e.g., single to multiple light sources for making shadows; single mirrors to multiple mirrors; simple lens refraction to a coin-in-pool situation) for small-group work in the classroom. Student groups observed real-world optical situations (or video depictions) and used our dynagramming tools to build scenes that make predictions and arguments to justify them based on scientific principles, definitions, or prior 
experiences. The dynagrams bypassed many difficulties students had in constructing paper-and-pencil or chalkboard diagrams. By composing dynagrams representations, students in a group could each graphically express predictions and then use those representations as indexical support for narrative explanations of light behavior in the situations they were modeling. Because the simulator knew how light rays depicted would propagate in the situation students modeled, they could then run their simulation models and discuss how well each of their graphical conjectures fit the actual results. Through students' creation and interpretation of these representations in group sense-making activities, the dynamic diagrams became symbolic vehicles for expressing students' conjectures about light behavior and the topic for negotiating group and individual understanding of technical language, concepts, procedures, and skills. The teacher could become a guide and facilitator of conceptual learning conversations, in which students would use new language and diagrams for thinking about optics in a socially visible context, and refinements of meaning could occur through peer and teacher negotiations of meaning.

In the third phase, we examined how the use of optics dynagrams changed the nature of instructional practices and resultant student learning outcomes in a classroom whose previous practice and learning outcomes had been documented for this science topic during the first phase. We conducted pre-post comparisons of student performance on everyday optics reasoning situations, post-only clinical interviews (for comparison with students working with the same teacher in the previous year), and longitudinal studies of small-group learning and conceptual change. Field notes and videotapes of student teamwork were recorded.

We found significant improvements for students on carefully designed measures of conceptual and reasoning skills in tasks involving light, vision, and image formation with mirrors and lenses. Specifically, students came to an expanded ontology for explaining optical phenomena (reasoning in terms of images behind mirrors, rays, sprays, point sources); an expanded set of diagram techniques for explaining optical phenomena (e.g., using the normal); and an expanded behavioral-causal model for explaining light behavior in situations. Ethnographic analyses using our field notes and videotapes of student teamwork demonstrated that students spent a significantly greater proportion of class time engaged in using and refining the meaning of new concepts than did non-dynagram students with the same teacher. Evidence also indicated the teacher perceived more teachable moments in this redesigned classroom environment and significantly altered the teaching to minimize diagram drawings and explanations we had shown to contribute to student misconceptions in previous instruction (e.g., drew fewer beams, and positively, to include), more ray sprays, and included eyes in diagrams where images form to emphasize the role of detectors.

Building on science learning studies such as dynagrams, we envision the extensive use of interactive multimedia technologies connected through tele- 
communications to create distributed multimedia learning environments (Pea \& Gomez, 1992). Distributed multimedia learning environments extend the teaching, learning, and material resources beyond individual classrooms. The technologies serve to enrich the capabilities of participants in a communication to express what they are thinking about, to capture traces of that thought in new forms of representation, and to jointly work to create new artifacts. But more important, they enable us to see what we are building together, as participants in a learning conversation in which the transformative nature of communication is in the foreground, so that we can co-construct a new understanding or other learning product.

The third set of developments involves addressing technical and design issues needed to achieve these objectives. Such teaching-learning and teamwork discourse often involves the use of complex symbolic representational systems in a discourse workspace between participants. The representations handled must be as diverse as diagrams, graphs on a whiteboard, lines of programming code on a computer screen, and aspects of a graphical simulation model. These representations come to serve as resources that enable speakers to engage in conversations about complex conceptual entities, such as slopes on a graph, or rays of light, or program subroutines. Participants can point to these entities, have discussion about them to clarify what is meant, describe how they are connected to other things, and co-construct common objects. Distributed multimedia learning environments could allow such key learning activities to take place over a distance, as remote collaborative activity including diverse media such as shared video, drawing, and data spaces is made possible. What technical developments will be required?

- Expanded message creation capabilities, including rich dynamic media of expression such as voice and video

- Means of integrating multimedia computing and communication capabilities

- Support for co-construction and communication of new forms of representation, including annotated video, animations of complex processes, and hypertexts

- Broad range of communication capabilities of the network for carrying message interchanges, including remote, synchronous audio and video, and shared data connections

Educational message services now are primarily text-only asynchronous electronic mail applications. We expect that a rich infrastructure for distributed multimedia learning environments will expand this niche to include synchronous and asynchronous multimedia messages. The National Geographic Society Kids Network lets students collaborate with distant scientists with text messages and static graphic displays. One can imagine young learners and scientists exchanging video that shows a climatological phenomena, executable programs that allow collaborators to study the same 
software models together, or distributed control and collaborative interpretation of readings from remote scientific instrumentation.

Today's communications networks do not have built-in mechanisms or protocols to talk about the class of applications that we suggest are needed to support distributed multimedia learning environments (DMLE). The goal of traditional communication protocols is to establish a call. This is just a simple request for connection initiated by one user and confirmed by another (Bussey \& Minzer, 1990). The task of developing protocols to support next-generation communications multimedia and multiuser applications-of which distributed multimedia learning environments are clearly a part-is at the core of much of the current research in communication science (e.g., Bussey \& Minzer, 1990; Clark \& Tennenhouse, 1990; Griffeth, 1991; Spears, 1987). DMLE will inherently make large demands on communication bandwidth resources and require extreme flexibility in call conferencing.

Finally, these three priority areas for development need to be investigated in tandem for the mutual benefits they may yield for understanding and improving practice. The needed study of conceptual change and conversational interaction must include attention to how discourse is carried out in specific communities of practice and ways in which concepts function and evolve in the activities of communities. We can certainly hope that our technology designs may be positively informed by the understandings gained from situated investigations of conceptual change and discourse in the communities of practice in which they come to function.

\section{CONCLUSION}

There is an important generalization of Geertz's point about symbols both representing and creating reality. The observation holds for the complex symbolic construction of CSCL models as well. We thus need to be deeply conscious about the birth of CSCL as a discipline and a new approach to thinking about learning and education. Through our deliberations and examples of CSCL, we not only describe but also change the realities possible for it.

\section{ACKNOWLEDGMENTS}

An earlier version of this article was presented at the 1992 annual meeting of the American Educational Research Association, San Francisco, CA, Symposium on "Instructional theories underlying the use of networked computers in the classroom."

I am grateful for research support of this work by the National Science Foundation Grant Nos. MDR88-55582 and MDR-9253462 by Apple Computer, Inc., External Research, and by Bellcore.

I thank my colleagues on the Dynagrams Project and others at the Institute 
for Research on Learning for extended discussions of these issues. Thanks to Louis Gomez of Bellcore for expanding my thinking about the consequences for distributed multimedia learning environments of the transformative view of communication. John Bransford and Jim Greeno provided much constructive advice for this manuscript.

\section{REFERENCES}

Borning, A., \& Travers, H. (1991). Two approaches to casual interaction over computer and video networks. CHI '9I Proceedings (pp. 13-19). New York: ACM.

Brown, A. L., \& Campione, J. C. (in press). Communities of learning and thinking: Or a context by any other name. Human Development.

Bussey, H. E., \& Minzer, S. E. (1990). A BISDN signaling protocol that supports multimedia interpersonal and information system applications. Bellcore.

Carey, J. W. (1989). Communication as culture: Essays on media and society. Boston: Unwin Hyman.

Clark, D. D., \& Tennenhouse, D. L. (1990). Architectural considerations for a new generation of protocols. Proceedings of SigComm ' 90.

Collins, A., Brown, J. S., \& Newman, S. (1989). Cognitive apprenticeship: Teaching the craft of reading, writing, and mathematics. In L. B. Resnick (Ed.), Knowing, learning, and instruction: Essays in honor of Robert Glaser. Hillsdale, NJ: Lawrence Erlbaum Associates, Inc.

Cruz, G. C., Gomez, L., \& Wilner, W. T. (1991). Tools to support conversational multimedia. Proceedings of GlobeComm '91.

Fish, R. S., Kraut, R. E., Root, R. W., \& Rice, R. E. (1993). Video as a technology for informal communication. Communications of the ACM, 36(1), 48-61.

Geertz, C. (1973). The interpretation of cultures. New York: Basic.

Griffeth, N. (1991). The negotiating agent model for establishing and modifying communications. Proceedings of the TINA-2 Workshop. Chantilly, France.

Hawkins, J. (1991). Technology-mediated communities for learning: Designs and consequences. Annals of the American Academy of Political and Social Science, 514, 159-174.

Lave, J., \& Wenger, E. (1991). Situated learning: Legitimate peripheral participation. New York: Cambridge University Press.

Levin, J. A., Riel, M., Miyake, N., \& Cohen, M. (1987). Education on the electronic frontier: Teleapprentices in globally distributed educational contexts. Contemporary Educational Psychology, 12, 254-260.

Newman, D., Griffin, P., \& Cole, M. (1989). The construction zone: Working for cognitive change in school. New York: Cambridge University Press.

Pea, R. D. (1991a). Designing classroom resources for conceptual change in science: Dynagrams (Final NSF Project Rep. No. MDR-88-55582). Palo Alto, CA: Institute for Research on Learning.

Pea, R. D. (1991b). Learning through multimedia. IEEE Computer Graphics and Applications, $11(4), 58-66$.

Pea, R. D. (1992). Augmenting the discourse of learning with computer-based learning environments. In E. de Corte, M. Linn, H. Mandl, \& L. Verschaffel (Eds.), Computer-based learning environments and problem-solving [NATO Series, subseries F: Computer and System Sciences] (pp. 313-343). New York: Springer-Verlag.

Pea, R. D. (1993). Learning scientific concepts through material and social activities: Conversational analysis meets conceptual change. Educational Psychologist, 28, 265-277.

Pea, R. D. (1993). Practices of distributed intelligence and designs for education. In G. Salomon (Ed.), Distributed cognitions (pp. 47-87). New York: Cambridge University Press.

Pea, R. D., \& Gomez, L. (1992). Distributed multimedia learning environments: Why and how? 
Interactive Learning Environments, 2(2), 73-109.

Riel, M. M., \& Levin, J. A. (1990). Building electronic communities: Success and failure in electronic networking. Instructional Science, 19, 145-169.

Roschelle, J. (1993). Learning by collaboration: Convergent conceptual change. The Journal of the Learning Sciences, 3, 235-276.

Rubin, A. (1992). The Alaska QUILL Network: Fostering a teacher community through telecommunication. Hillsdale, NJ: Lawrence Erlbaum Associates, Inc.

Ruopp, R., Gal, S., Drayton, B., \& Pfister, M. (Eds.). (1993). LabNet-Toward a community of practice: Hillsdale, NJ: Lawrence Erlbaum Associates, Inc.

Scardamalia, M., \& Bereiter, C. (1991). Higher levels of agency for children in knowledgebuilding: A challenge for the design of new knowledge media. The Journal of the Learning Sciences, 1, 37-68.

Scardamalia, M., \& Bereiter, C. (in press). Schools as knowledge-building communities. In S. Strauss (Ed.), Human development (Vol. 5). Norwood NJ: Ablex.

Spears, D. R. (1987). Broadband ISDN switching capabilities from a services perspective. IEEE Journal on Selective Areas in Communication, SAC-5, 8, 1222-1230.

Tang, J. C., \& Minneman, S. L. (1991). VideoWhiteBoard: Video shadows to support remote collaboration. Proceedings of CHI' 91 (pp. 315-322). New Orleans, LA.

Tinker, R. (1992). Thinking about science. Princeton, NJ: CEEB.

Waugh, M., \& Levin, J. A. (1989). TeleScience activities: Educational uses of electronic networks. Journal of Computers in Mathematics and Science Teaching, 8, 29-33. 